\title{
ANTIMALARIAL USE IN THE MANAGEMENT OF MALARIA IN PREGNANCY IN A TERTIARY CARE SETTING IN SOKOTO, NORTH WESTERN NIGERIA
}

\section{*Jimoh $\mathrm{AO}^{1}$, Shehu $\mathrm{CE}^{2}$, Panti $\mathrm{AA}^{2}$, Sani $Z^{3}$, Abubakar $\mathrm{K}^{4}$, and Danzaki AM ${ }^{4}$}

Department of Pharmacology \& Therapeutics, College of Health Sciences, Usmanu Danfodiyo University Sokoto - Nigeria ${ }^{1}$, Department of Obstetrics \& Gynaecology ${ }^{2}$ and Family Medicine ${ }^{3}$, Usmanu Danfodiyo University Teaching Hospital Sokoto - Nigeria, Department of Pharmacology \& Toxicology, Faculty of Pharmaceutical Sciences, Usmanu Danfodiyo University Sokoto - Nigeria ${ }^{4}$.

Correspondence: Dr Abdulgafar O. Jimoh,

Department of Pharmacology \& Therapeutics, College of Health Sciences, Usmanu Danfodiyo University Sokoto - Nigeria. P.O. Box 2005, Sokoto, Sokoto State Phone; +2348035950558 Email; layidotcom@yahoo.com

\section{ABSTRACT}

Background: Malaria in pregnancy still remains a public health concern that needs to be addressed; it ranks among the commonest causes of complications in pregnancy, leading to maternal morbidity and mortality.

Objectives: This study is aimed at reviewing the pattern of antimalarial use in the management of malaria in pregnancy so as to determine the compliance of prescribers to recommended guidelines and policies of drug use in pregnancy, and review the core prescribing indicators.

Methodology: This was a retrospective study conducted between 1st January 2012 to 31st December 2012 at the Department of Obstetrics and Gynecology Usmanu Danfodiyo University teaching hospital (UDUTH), Sokoto - Nigeria. Case notes of pregnant women seen and managed as a case of Malaria in pregnancy within the study period were retrieved. Data analysis was done using the statistical package for social sciences (SPSS) 17.0.

Results: Four hundred and eighty two case folders were retrieved within the study period. The mean age was $26.8 \pm 5.01$ years. Artemisinin combination therapy (ACTs) were the most

commonly prescribed drugs; Artemether-lumefantrine $68 \%$ (328), artemether $42(8.7 \%)$, artesunate and artesunate-SP each $20(4.1 \%)$ of the patients respectively. The diagnostic approach was clinical symptomatology $(62.2 \%)$ and Laboratory confirmed in only (37.8\%). Generic prescribing accounted for $48.9 \%$, injectables and antibiotics accounted for $21.2 \%$ and $43.2 \%$ respectively.

Conclusions and Recommendations: Optimum adherence to recommended treatment guidelines is advocated. ACTs were the most prescribed antimalarial irrespective of the trimester. There was lack of compliance with prompt parasitological confirmation by microscopy or Rapid Diagnostic Tests (RDTs) in many of the patients suspected of malaria. Core prescribing indicators were not in consonance with standard reference values in this study. An urgent need for continuing medical education and professional development for all health service providers concerning the current WHO and the National policy on malaria treatment in pregnancy and rational drug use.

Key words: Antimalarial use, Malaria in pregnancy, Tertiary care, Sokoto-Nigeria.

\section{INTRODUCTION}

The deleterious consequences of malaria infection during pregnancy for both the mother and her foetus have been widely reported. Malaria infection during pregnancy poses substantial risk to the mother, her fetus, and the neonate. ${ }^{1}$ Worldwide, malaria infestation in pregnancy is a major public health concern and ranks amongst the commonest complications of pregnancy in Nigeria. It is an important preventable cause of significant maternal morbidity and mortality with associated fetal wastage. ${ }^{2}$ Malaria is an important cause of maternal anemia, intra-uterine growth restriction, intrauterine fetal death, stillbirth, premature delivery, low birth weight (LBW), peri-natal and neonatal morbidity and mortality and postpartum morbidity. ${ }^{3}$ In Nigeria, Malaria is also responsible for $25 \%$ of infant mortality; causes $30 \%$ of all childhood deaths ${ }^{4}$ and is associated with about $11 \%$ of maternal deaths. ${ }^{4}$

The current World Health Organization guidelines for the treatment of uncomplicated malaria in pregnancy recommend an artemisinin-based combination therapy (ACT) as the first-line treatment in the second and third trimesters of pregnancy, while oral quinine plus clindamycin is recommended for treatment in the first trimester. ${ }^{1}$ The Nigerian National antimalarial guideline and treatment policy recommends intermittent preventive therapy (IPT) with Sulfadoxin / pyrimethamine as the mode of prophylaxis in pregnancy and for treatment of clinical infestations, quinine is recommended as first line agent in all trimesters, while artemisinin based combination (ACT) is considered safe second line agents in second and third trimesters. ${ }^{5}$ However, in the first trimester the ACT can be used where there are no suitable alternatives.

Pregnancy is a time of profound physiological changes in a woman's body. These unique changes challenge clinicians managing disease states during pregnancy in the selection of medications best suited to treat their patients. Maternal drug use during pregnancy may pose a teratogenic risk to the foetus. However, the recommendation to avoid all drugs during early pregnancy is unrealistic and may be dangerous. ${ }^{6}$ The pharmacokinetics, dosing regimen, efficacy and safety profile of antimalarials currently used to treat and prevent falciparum malaria in adults and children are well-described. This is not the case in pregnancy where the limited data available in each of these areas makes it difficult to predict which drugs are likely to be the best candidates for treating and preventing infection. Many antimalarials are contraindicated in pregnancy (e.g. primaquine, doxycycline, halofantrine, tafenoquine), whilst the safety of several promising candidates remains unclear. ${ }^{7}$ Hence, the need to study the pattern of drug 
use among pregnant women generally, so as to determine the adherence to guidelines or the possible consequence of nonadherence to recommended guidelines, or accidental beneficial outcomes of such non-adherence.

Therefore, in the light of the above; this work is aimed at reviewing the practice of prescribers in the management of malaria in pregnancy in relation to compliance to recommended guidelines and policies of drug use in pregnancy, and to analyze the prescribing patterns in the Department of Obstetrics \& Gynaecology, Usmanu Danfodiyo University Sokoto - Nigeria using the WHO/INRUD core prescribing indicators for health facilities.

\section{METHODS}

The study was conducted at the Department of Obstetrics and Gynaecology, Usmanu Danfodiyo University Teaching Hospital (UDUTH), a tertiary care hospital located in Wamakko Local Government Area of Sokoto State. The department has about eleven consultants, five senior registrars, twenty two registrars and nine house officers. It also is composed of four units, four wards, one laboratory, and an estimated bed capacity of about eighty beds as at the time of the study. This was a retrospective study conducted between $1^{\text {st }}$ January, 2012 to $31^{\text {st }}$ December, 2012. A total of five hundred and twenty seven (527) cases of malaria in pregnancy were managed within the study period however only four hundred and eighty two (482) patients records were retrieved with full information giving a retrieval rate of $91.5 \%$. Case notes of pregnant women that diagnosed and managed for malaria in pregnancy were retrieved for the study. The informations retrieved includes; patient socio-demographic data and obstetric history, mode of diagnosis of malaria in pregnanany including laboratory investigations, and medications. The pregnant women and their corresponding drug use were classified according to trimester and compared to available recommended guidelines. Data collected from patient case notes was entered into a spread sheet, and analysed by descriptive statistics using the statistical package for social sciences (SPSS) 17.0. The WHO/INRUD methods of determining core prescribing indicators were employed. The average number of medicines per encounter was calculated by dividing the total number of drugs by the number of encounters. Percentage encounter with generic name, percentage encounter with antibiotics, and percentage of encounter with injections were determined by dividing the number of occurrence by the total number of event, respectively, and multiplying by 100 .

\section{RESULTS}

Four hundred and eighty two subject's case notes were retrieved for the study. Demographics obtained showed that the mean age for the study population was $26.8 \pm 5.01$ years. The mean age of primigravidae was $22.6 \pm 3.11$ and that of grand-multigravidae was 33.3 \pm 4.18 . Primigravidae made up to 128 (26.6\%), while $352(73 \%)$ had at least one previous birth (multigravida), however in 2 cases $(0.4 \%)$ the gravidity was not indicated. Out of the total number of the study subjects, $44(9.1 \%)$ were in the first trimester, $166(34.4 \%)$ were in the second and $202(41.9 \%)$ were in the third trimester of pregnancy respectively(Table 1).

The result also showed that, fever was the commonest presenting complain found in $340(70.5 \%)$ of the patients, headache was reported by $264(54.8 \%)$ and $140 \quad(29 \%)$ complained of vomiting. It should be noted that only the first three presenting complains were considered during the study. Urinary tract infection (UTI) was shown to be the most common co-morbidity present in $146(68.2 \%)$ of the patients, followed by acid peptic disorders (including peptic ulcer, dyspepsia and reflux oesophagitis) in $20(9.4 \%)$ and gastroenteritis in 6 $(2.8 \%)$ of the patients. Upper respiratory tract infection (URTI) was also present in $6(2.8 \%)$ of the patients(Table 2).

All the patients involved in the study were diagnosed using either clinical symptomatology used in 300 $(62.2 \%)$ of the patients or laboratory examination employed in 182 $(37.8 \%)$ patients as a basis for antimalarial drugs prescription before antimalarial drug prescription. Out of the 182 patients that were requested to do the laboratory examination (blood film for MP), 162 (89.0\%) were positive for malaria and $20(11.0 \%)$ had no evidence of malaria parasite.

A total of 1494 drugs were prescribed in all with an average drug per prescription of 3.1. Injectables appeared in up to $102(21.2 \%)$ of the encounters, antibiotics were shown to have appeared in $210(43.6 \%)$ of the encounters, and $730(48.86 \%)$ of the drugs were prescribed using their generic names(Table 3). Use of Arthemeter-Lumefantrine alone or in combination with other anti-malarial was shown to be the most common regimen employed in the study population, up to $50 \%$ in the first trimester, $73.5 \%$ in the second trimester and $67.3 \%$ in the third trimester. This is followed by other artemisinin derivatives $(50 \%)$ in first trimester, $(25.2 \%)$ in second trimester and $(28.9 \%)$ in the third trimester. SP monotherapy was used in just $2(1.2 \%)$ second trimester and $8(4 \%)$ third trimester episodes. Therefore regardless of the trimester $\mathrm{ACT}^{\mathrm{s}}$ were shown to be the most common prescribed treatment regimen in the patients during the study period (Table 4).

\section{DISCUSSION}

The mean maternal age obtained from the study $26.8 \pm 5.01$ is similar to that obtained in Benin City and Maiduguri respectively, $25.16 \pm 3.62$ ${ }^{4}$ and $24.93 \pm 5.43$. ${ }^{9}$ Majority of the study population were full time housewives which may not be unconnected to the socio-cultural and religious background of majority of the patients with Hausa as the major tribe and Islam as the main religion. Multigravid women form the majority of the patients in the study population. This is consistent with the finding in Maiduguri ${ }^{9}$ but in contrast with the finding in Benin City where primigravid women were the majority. ${ }^{4}$ The high turnout of multigravida may not be unconnected to exposure and experience of the women who are aware of its importance in preventing pregnancy related complications. Pregnant women in their third trimester formed bulk of the study subjects, which is similar to findings 
in India and eastern Sudan where third trimester makes up the highest proportion of the study population ${ }^{10,11}$ but in contrast to the findings of Eze et al. and Okoro and Nwambo, that reported higher second trimester patients. $^{4,9}$ The least number of first trimester attendants is consistent with the finding in Maiduguri ${ }^{9}$. This may be attributed to the fact that most of the pregnant women reported for the first time to the ANC clinic well after the first trimester.

The most recent guidelines for the treatment of malaria from WHO recommend that, in all settings, clinical suspicion of malaria should be confirmed with a parasitological diagnosis (Rapid diagnostic test RDT, or standard microscopy), except in places where parasitological diagnosis is not possible ${ }^{1}$. The study center is a tertiary health facility where a more specific diagnosis is not only required but available. However, results showed that majority $(62.2 \%)$ of malaria episodes were diagnosed using clinical symptomatology at the time of the study though a good number of the patients were asked to go for MP test but the test were not used as a guide for diagnosis and antimalarial therapy as recommended. This was in consonance with the result of studies carried out in Benin City and Maiduguri, $^{4,9}$ where most of the antimalarial prescriptions were based on clinical signs and symptoms, a study in Lagos also showed that only $7.7 \%$ of results returned positive malaria slides. ${ }^{12}$ Using empirical formulae may result in over diagnosis of malaria, overuse of the antimalarial, and late diagnosis of other febrile illnesses which may have deleterious consequences. ${ }^{13}$

Going by the WHO guideline for the management of malaria in pregnancy; these results suggest that adherence to treatment guidelines for management of malaria in pregnancy in first trimester can be optimised. Almost all malaria episodes occurring during the first trimester of pregnancy were treated with Artemehter Lumefantrine, (AL) as the first line agent. Artemisinins are contraindicated during the first trimester of pregnancy due to embryo-foetal toxicity observed in studies of rats and rabbits and limited safety data of early pregnancy use in humans. However, the WHO does recommend first trimester use of ACT if the treatment is believed to be life-saving for the mother and other available anti-malarial drugs are considered unsuitable. Oral quinine plus clindamycin for seven days (or quinine monotherapy if clindamycin is not available) is the recommended first-line treatment in the first trimester of pregnancy for uncomplicated malaria. Treatment with oral quinine is generally believed not to be toxic to the fetus, irrespective of trimester of use, although data are limited. ${ }^{1}$ The treatment regimen in the second and third trimesters involves the use of $\mathrm{ACT}^{\mathrm{s}}$. AL alone or in combination accounts for over $80 \%$ of the regimen prescribed. This was observed to be in line with the WHO and the federal ministry of health guidelines for the management of malaria in pregnancy in the second and third trimesters.

This is consistent with the findings in Maiduguri and Uganda ${ }^{9,13}$ that also reported poor compliance to recommended guidelines of managing malaria in pregnancy in the first trimester. This may be in consideration that the use of oral quinine is particularly problematic considering its marked side effects, poor compliance, and a long treatment course requiring a dose to be taken every 8 hours for 5 to 7 days. ${ }^{14}$ Furthermore $P$. falciparum resistance to quinine has been reported. One such report was in South East $\mathrm{Asia}^{13}$ which may eventually limits the effectiveness of the regimen. SP monotherapy was observed in $5.2 \%$ of the study population. This is similar to the finding in Uganda and north eastern Nigeria. $^{9,13} \mathrm{SP}$ is not recommended for treatment of symptomatic malaria in pregnancy ${ }^{1}$ in order to preserve its efficacy for IPT. The use of Chloroquine (CQ) combined with AL was also observed in a small proportion $(4.5 \%)$ of the first trimester episodes despite the fact that CQ has been withdrawn from the guideline in the treatment of malaria in pregnancy. ${ }^{1}$ Reason may be that, the prescriber put in to consideration the socioeconomic status of the patient, considering that it's cost effective and safe for the patient. However, these findings were supported by a study carried out in Benin City in which 71 (73\%) of the respondents reported exclusively using CQ as first line therapeutic agent because of its efficacy, cost, safety and availability. ${ }^{15}$ Similar result was also reported with $1.25 \%$ of the total drugs used for treatment in a study in Maiduguri, north eastern Nigeria.'

The use of antibiotics was higher than that reported by in Benin City. However this could have been as a result of the level of co-morbidity with UTI presented by $30.3 \%$ of the study population which more than doubled that reported in Benin City. The average number of drugs per encounter differs from the standard set by WHO (1.6-1.8). However similar values have been reported in Nigeria. ${ }^{4,16}$ The higher number may have resulted because of the various co-morbid presentation by the patients. The implication being that, patient may have more drugs than they can cope with in terms of cost and compliance and also increase the risk of drug-drug interactions. ${ }^{16}$ The occurrence of encounter with injectable was within range in this study this was in contrast with findings reported in some part of Nigeria, ${ }^{17}$ but similar findings in Lagos. ${ }^{18}$ This is commendable owing to the fact that their use may be inconveniencing, expensive, requires expertise, may introduce infection and abscess formation, and may introduce high concentration of drug in the plasma, which could lead to various toxicity issues in the pregnant women exposed. It may also be that, the severity of the disease with majority of the patients (61.8\%) presenting with a mild episode of malaria, and been treated and discharged as out-patients.

Rational drug use is defined as judicious use of drug, and focuses on appropriate adoption of drug therapy. It comprises of rational prescribing, dispensing, and utilization of drugs. Rational prescribing involves the selection of the best drug from the available ones, and must be given in the appropriate dose, and regimen. One of the features of irrational 
prescribing is extravagant prescribing which involve prescribing newer or expensive drugs, when less expensive ones will be equally effective and safe for use. 19

Evaluation of the names of drugs used in the study showed almost $50 \%$ of the drugs were prescribed using their generic name. Prescribing using brand names was common in the country. This was supported by previous studies in Nigeria. ${ }^{4,9,16,20}$ and was even much higher than $7.4 \%$ reported in Maiduguri. ${ }^{9}$ This means that the prescribers were not complying fully with WHO recommendation that drugs should be prescribed using their international non-proprietary names. The implication of using non generic prescribing; may lead to increased cost and also difficulty in finding the prescribed drug which may in turn decrease compliance resulting in poor outcome of drug therapy. Possible factors responsible for this trend include; the influence of drug promotion activities, lack of continuing education on the principles of rational prescribing, non-familiarity with generic names of drugs among the prescribers and also influence of pharmaceutical company marketing representatives. ${ }^{9}$

\section{CONCLUSION AND RECOMMENDATIONS}

Adherence to recommended treatment guidelines and policies was not optimum. Clinical symptomatology rather than laboratory confirmation was the main mode of diagnosis. Average number of drugs per prescription, percentage encounter with antibiotics, and generic prescription were all not in consonance with the standard reference values in this study.

Shortfalls in the use of available recommended medications for malaria in pregnancy especially in the first trimester, are part of the factors that justify the pressing need for vigorous research towards finding better alternatives for use in pregnancy. There is an urgent need for continuing medical education and professional development for all health service providers concerning the current WHO guidelines and the National policy on malaria treatment in pregnancy and rational drug use.

\section{REFERENCES}

1. World Health Organization. Guidelines for the Treatment of Malaria. $2^{\text {nd }}$ Edition, WHO Press, Geneva, Switzerland 2010, 47.

2. Rogerson S.J, Mwapasa V, Meshnick S.R. Malaria in pregnancy: Linking immunity and pathogenesis to prevention. American journal of tropical medicine and hygiene. 2007; (6);77.

3. Sangaré LR, Weiss NS, Brentlinger PE, Barbra A. Pattern of Antimalarial Drug Treatment among Pregnant women in Uganda. Malaria journal, 2011: 10; 152.

4. Ejezie GC., Ezedinachi EN., Usanga EA., Gemade EI., Ikpatt NW., Alaribe AA. Malaria and its treatment in rural village of Aboh Mbaise Imo Nigeria. Acta Trop. 1991;48:17-24.

5. Federal Ministry of Health National Malaria and Vector Control Division. National Antimalarial treatment guidelines and policy. AbujaNigeria 2005.

6. Eze UI, Eferakeya AE, Oparah AC, Enato EF. Assessment of prescription profile of pregnant women visiting antenatal clinics. Pharmacy Practice 2007: 5; 135 139.

7. Vallely A, Vallely L, Changalucha J, Greenwood B, Chandramohan D. Intermittent preventive treatment for malaria in pregnancy in Africa: What's new, what's needed? Malaria journal 2007: 6:16.

8. World Health Organization. How to investigate drug use in health facilities. Selected drug use indicators. WHO/DAP/93.1.

9. Okoro R. N., Nwambu J.O., Evaluation of physicians' prescribing patterns of antimalarial drugs during pregnancy at the obstetrics and gynaecology department of a teaching hospital in Maiduguri, Borno state, Nigeria. Int. J Pharm Biomed Sci 2012; 3(2):39-46.

10. Sharma R., Kapoor B., Verma U. Drug utilization pattern during pregnancy in North India. Indian J Med Sci 2006;60:277-87.
11. Adam I, Khamis AH, Elbashir MI. Prevalence and risk factors for Plasmodium falciparum malaria in pregnant women of Eastern Sudan. Malaria journal 2005:4:18.

12. Agomo CO., Oyibo WA, Anorlu RI, Agomo PU. Prevalence of malaria in pregnant women in Lagos, South western Nigeria. Korean J parasitol 2009:47(2): 179-183.

13. Sangare LR, Weiss NS, Brentlinger PE, Barbra A. Pattern of Antimalarial Drug Treatment among Pregnant Women in Uganda. Malarial Journal, 2011;10:152.

14. Brunton LL, Lazo JS, Parker KL: Goodman and Gilman's the pharmacological basis of therapeutics, $11^{\text {th }}$ edition, McGraw-Hill Inc, 2006: 87.

15. Omo-Aghoja LO, Aghoja CO, Oghagbon K., Omo-Aghoja VW, Esume C. Prevention and treatment of malaria in pregnancy in Nigeria: obstetrician's knowledge of guidelines and policy changes-a call for action. Journal of Chinese Clinical Medicine 2008; 3: 114-120.

16. Jimoh AO., Etuk EU., Sani Z., Hudu AS. The pattern of antibiotic use in a family medicine Department of a tertiary Hospital in Sokoto, North Western Nigeria. Journal of clinical and diagnostic research. 2011;5(3):566-569.

17. Isah AO, Ohaju-obodo A., Isah EC, Ozemoya O. Drug use profile in a Nigerian city Hospital, pharmacoepidemiol drug safety 1997;6:319-24.

18. Odusanya OO. Drug use indicators at a secondary health care facility in Lagos, Nigeria. A Journal community medicine and primary health care, 2004;16(1):21-24.

19. EMDEX. The Complete Drug Formulary for Nigerian's Health Professionals. LindozBooks, Canada 2010.

20. Akande TM., Ologe M,. Prescription pattern in a secondary health facility in Ilorin Nigeria. Annal Afr. Med. 2007; 6 (4): 186-189. 
Table 1: Demographic data and Obstetric history

\begin{tabular}{|c|c|}
\hline $\mathrm{N}=482$ & n (\%) \\
\hline 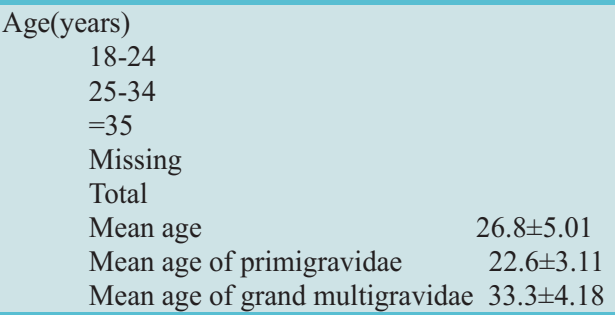 & $\begin{array}{l}162(33.61) \\
276(57.3) \\
42(8.71) \\
2(0.4) \\
482(100)\end{array}$ \\
\hline $\begin{array}{l}\text { Occupation } \\
\text { Full time house wife } \\
\text { Trader } \\
\text { Civil servant } \\
\text { Others } \\
\text { Missing } \\
\text { Total }\end{array}$ & $\begin{array}{l}394(81.7) \\
22(4.6) \\
24(5.0) \\
40(8.3) \\
2(0.4) \\
482(100)\end{array}$ \\
\hline $\begin{array}{l}\text { Educational status } \\
\text { None } \\
\text { Islamiyya } \\
\text { Primary } \\
\text { Secondary } \\
\text { Tertiary } \\
\text { Missing } \\
\text { Total } \\
\end{array}$ & $\begin{array}{l}70(14.5) \\
180(37.3) \\
34(7.1) \\
80(16.6) \\
116(24.1) \\
2(0.4) \\
482(100)\end{array}$ \\
\hline $\begin{array}{l}\text { Gravidity } \\
\text { Primigravida } \\
\text { Multigravida } \\
\text { Missing } \\
\text { Total }\end{array}$ & $\begin{array}{l}128(26.6) \\
352(73) \\
2(0.4) \\
482(100)\end{array}$ \\
\hline $\begin{array}{l}\text { Trimester } \\
\qquad \begin{array}{l}1^{\text {st }} \text { Trimester }(0-12 \text { weeks }) \\
2^{\text {nd }} \text { Trimester }(13-24 \text { weeks }) \\
3^{\text {rd }} \text { Trimester }(25-40 \text { weeks }) \\
\text { Missing } \\
\text { Total }\end{array}\end{array}$ & $\begin{array}{l}44(9.1) \\
166(34.4) \\
202(41.9) \\
70(14.5) \\
482(100)\end{array}$ \\
\hline $\begin{array}{l}\text { Patient } \\
\qquad \begin{array}{l}\text { In-patient } \\
\text { Out patient } \\
\text { Total }\end{array}\end{array}$ & $\begin{array}{l}203(42.1) \\
279(57.9) \\
482(100)\end{array}$ \\
\hline
\end{tabular}

Table 2: Co-morbidity

\begin{tabular}{|l|l|}
\hline N=214 & $\mathbf{n}(\mathbf{\%})$ \\
\hline Co-morbidity & \\
Urinary Tract Infection (UTI) & $146(68.2)$ \\
Gastroenteritis (GE) & $6(2.8)$ \\
Acid Peptic Disorders (APD) & $20(9.4)$ \\
Pelvic Inflammatory Disease (PID) & $2(0.9)$ \\
Hyperemesis gravidarum & $4(1.9)$ \\
Upper Respiratory Tract Infection & $6(2.8)$ \\
Diabetes in pregnancy & $2(0.9)$ \\
UTI+GE & $6(2.8)$ \\
UTI+Seizure & $2(0.9)$ \\
UTI+APD & $10(4.7)$ \\
URTI+Haemorrhoids & $2(0.9)$ \\
URTI+Asthma & $2(0.9)$ \\
UTI+Vaginal candidiasis & $2(0.9)$ \\
UTI+PID & $4(1.9)$ \\
Total & $214(100)$ \\
\hline
\end{tabular}

Table 3: WHO/INRUD core prescribing indicators

\begin{tabular}{|l|l|}
\hline Core Prescribing Indicators & n (\%) \\
\hline \% Encounter with Injectables prescribed & $102(21.2)$ \\
\% Encounter with Antibiotics prescribed & $210(43.6)$ \\
Generic prescribing & $730(48.9)$ \\
Total drug count $\quad 1494$ & \\
Average drug per prescription $\quad 3.1$ & \\
\hline
\end{tabular}

Table 4: Antimalarial use based on trimester

\begin{tabular}{|c|c|c|c|}
\hline Trimester/Drugs & n $(\%)$ & WHO Guideline & National Guideline \\
\hline $\begin{array}{l}1^{\text {st }} \text { trimester }(\mathrm{N}=44) \\
\text { ACT } \\
\text { AMT } \\
\text { AL+CQ } \\
\text { Total } \\
2^{\text {nd }} \text { trimester }(\mathrm{N}=\mathbf{1 6 6}) \\
\text { ACT } \\
\text { SP } \\
\text { AMT } \\
\text { AL+SP } \\
\text { Total } \\
3^{\text {rd }} \text { trimester }(\mathrm{N}=\mathbf{2 0 2}) \\
\text { ACT } \\
\text { SP } \\
\text { AMT } \\
\text { AL+SP } \\
\text { Total }\end{array}$ & $\begin{array}{l}30(68.2) \\
12(27.3) \\
2(4.5) \\
44(100) \\
\\
142(85.5) \\
2(1.2) \\
18(10.8) \\
4(2.4) \\
166(100) \\
\\
152(75.3) \\
8(4) \\
40(19.9) \\
2(1) \\
202(100)\end{array}$ & $\begin{array}{l}\text { Quinine+Clindamycin } \\
\text { OR } \\
\text { Quinine alone (if } \\
\text { clindamycin not } \\
\text { available) } \\
\text { ACT }^{\text {s }} \\
\\
\text { ACT }^{\mathrm{s}}\end{array}$ & $\begin{array}{l}\text { Quinine } \\
\text { OR } \\
\text { ACT }^{\text {s }} \text { (if there are no } \\
\text { suitable alternatives) } \\
\text { ACT }^{\text {s }}\end{array}$ \\
\hline
\end{tabular}

